University of Wollongong

Research Online

Australian Institute for Innovative Materials -

Papers

Australian Institute for Innovative Materials

$1-1-2015$

Contamination mitigation strategies for scanning transmission electron microscopy

David R. G Mitchell

University of Wollongong, dmitchel@uow.edu.au

Follow this and additional works at: https://ro.uow.edu.au/aiimpapers

Part of the Engineering Commons, and the Physical Sciences and Mathematics Commons

Research Online is the open access institutional repository for the University of Wollongong. For further information contact the UOW Library: research-pubs@uow.edu.au 


\title{
Contamination mitigation strategies for scanning transmission electron microscopy
}

\begin{abstract}
Modern scanning transmission electron microscopy (STEM) enables imaging and microanalysis at very high magnification. In the case of aberration-corrected STEM, atomic resolution is readily achieved. However, the electron fluxes used may be up to three orders of magnitude greater than those typically employed in conventional STEM. Since specimen contamination often increases with electron flux, specimen cleanliness is a critical factor in obtaining meaningful data when carrying out high magnification STEM. A range of different specimen cleaning methods have been applied to a variety of specimen types. The contamination rate has been measured quantitatively to assess the effectiveness of cleaning. The methods studied include: baking, cooling, plasma cleaning, beam showering and UV/ozone exposure. Of the methods tested, beam showering is rapid, experimentally convenient and very effective on a wide range of specimens. Oxidative plasma cleaning is also very effective and can be applied to specimens on carbon support films, albeit with some care. For electron beam-sensitive materials, cooling may be the method of choice. In most cases, preliminary removal of the bulk of the contamination by methods such as baking or plasma cleaning, followed by beam showering, where necessary, can result in a contamination-free specimen suitable for extended atomic scale imaging and analysis.
\end{abstract}

\section{Keywords}

contamination, mitigation, electron, strategies, microscopy, scanning, transmission

Disciplines

Engineering | Physical Sciences and Mathematics

\section{Publication Details}

Mitchell, D. R. G. (2015). Contamination mitigation strategies for scanning transmission electron microscopy. Micron, 73 36-46. 
Contamination mitigation strategies for scanning transmission electron microscopy

D. R. G. Mitchell

Electron Microscopy Centre, Australian Institute for Innovative Materials, Innovation Campus, University of Wollongong, North Wollongong, NSW 2500, Australia

*Corresponding author

dmitchel@uow.edu.au

tel +61 442215312

\begin{abstract}
Modern scanning transmission electron microscopy (STEM) enables imaging and microanalysis at very high magnification. In the case of aberration-corrected STEM, atomic resolution is readily achieved. However, the electron fluxes used may be up to three orders of magnitude greater than those typically employed in conventional STEM. Since specimen contamination often increases with electron flux, specimen cleanliness is a critical factor in obtaining meaningful data when carrying out high magnification STEM. A range of different specimen cleaning methods have been applied to a variety of specimen types. The contamination rate has been measured quantitatively to assess the effectiveness of cleaning. The methods studied include: baking, cooling, plasma cleaning, beam showering and UV/ozone exposure. Of the methods tested, beam showering is rapid, experimentally convenient and very effective on a wide range of specimens. Oxidative plasma cleaning is also very effective and can be applied to specimens on carbon support films, albeit with some care. For electron beam-sensitive materials, cooling may be the method of choice. In most cases, preliminary removal of the bulk of the contamination by methods such as baking or plasma cleaning, followed by beam showering, where necessary, can result in a contamination-free specimen suitable for extended atomic scale imaging and analysis.
\end{abstract}

Keywords

Scanning transmission electron microscopy, hydrocarbon contamination, specimen cleaning

\title{
1. Introduction
}

Hydrocarbon contamination has been a limiting factor in electron microscopy since the technique was invented. Vacuum systems using oil-based rotary and diffusion pumps can produce back-streaming of oil. This oil vapour can then crack under the electron beam, resulting in the build-up of carbon on the area under investigation (Ennos, 1953). Improvements in pump oils and vacuum technology in general, have greatly diminished the contribution of the vacuum system to the contamination problem. Oil-free systems, such as scroll, turbo-molecular and ion pumps have largely replaced oil-based pumps for evacuating columns (Williams and Carter, 1996). When used in conjunction with liquid nitrogen-cooled cold traps, 
much cleaner vacuum systems have resulted. Today, the majority of the contamination arrives on the specimen (Egerton et al., 2004; McGilvery et al., 2012; Soong et al., 2012).

Scanning transmission electron microscopy has often been limited by contamination on the specimen, especially where long mapping scans at high magnification are carried out. Strategies for dealing with contamination have been developed, and include plasma cleaning (Griffiths A. J. V., 2010; Isabell et al., 1999; McGilvery et al., 2012; Zaluzec, 2001; Zaluzec et al., 1997), baking (Egerton et al., 2004; McGilvery et al., 2012; Soong et al., 2012; Williams and Carter, 1996), exposure to ultraviolet light and ozone (Hoyle et al., 2011; Soong et al., 2012) , cooling (Egerton and Rossouw, 1976; Hren, 1986) and beam showering (Egerton et al., 2004). The need for such contamination mitigation strategies has been made even more pressing with the advent aberration corrected STEM. Atomic resolution imaging and mapping is now routine, and the localised electron doses may be greater by up to three orders of magnitude than those used in conventional STEM. Often, contamination is the major limiting factor. This manifests itself as reduced lattice contrast, compromised EELS analysis (Schamm and Zanchi, 2001) and loss of resolution due to beam broadening. In general carbon deposition varies between a minor nuisance and a major obstacle.

Microscopists often develop heuristics for decontamination treatments, but these may be overly conservative and waste valuable column time. This article describes a quantitative evaluation of range of contamination mitigation techniques, to understand not only which are best suited to particular applications but also to optimise the duration of treatments required for a specific outcome.

\section{Materials and Methods}

Various specimens were used to assess different types of contamination. These included as-received carbon films ( $25 \mathrm{~nm}$ thickness) from a commercial vendor, a commercial thin oxide reference film, crosssections from a semiconductor device and a bulk silicon thin foil - both produced by conventional ion milling methods. Holey carbon films loaded with a nanoparticulate were prepared by dispersing the phase in organic solvent. In the case of PtNi, $\mathrm{n}$-hexane was used, as these nanoparticles will not disperse well in polar solvents. For PbS, ethanol was used. PtNi synthesis used a long chain surfactant (oleylamine) of low volatility, while PbS involved thiolactic acid and methanol. Organic residue from synthesis was found in both phases, a commonly encountered scenario when studying chemically synthesized nanoparticulates with electron microscopy. Clean holey carbon films were also deliberately contaminated by placing a drop of acetone on them, shaking off the excess and allowing to dry. A summary of the experimental conditions evaluated is shown in Table 1

To measure the carbon contamination rate, regions of the specimen were scanned using a standard set of STEM conditions on a JEOL ARM200F operating at 200kV: Probe 5C, Condenser Aperture 40um, probe current $0.155 \mathrm{nA}$, scanning at $1 \mathrm{mx}$ magnification $(170 \times 170 \mathrm{~nm})$, for durations of 1 to 16 minutes. Scanning was done in a fast scan Preview mode: $512 \times 512$ pixels $\times 1.86 \mu$ s dwell time to produce frame rates of about 1 per second (allowing for overscan and settling time). The current density based on the nominal pixel area $\left(0.11 \mathrm{~nm}^{2}\right)$ was $1.41 \mathrm{nA} . \mathrm{nm}^{2}$. In reality, the probe diameter $(0.1 \mathrm{~nm})$ was much smaller than the pixel size leading to a current density of 19.7nA. $\mathrm{nm}^{2}$. The electron fluxes are reported in Table 2. Electron beam heating effects were calculated using the model of Egerton et al. (Egerton et al., 2004). Temperature rises 
were highest for low thermal conductivity carbon support films. Beam showering at 23.3nA resulted in a $5^{\circ} \mathrm{C}$ temperature rise, whereas at the measurement current $(0.155 \mathrm{nA})$, the value was just $0.04^{\circ} \mathrm{C}$. In the case of $\mathrm{Si}$ foils, where the thermal conductivity is some $90 \mathrm{x}$ greater than that of carbon, the temperature rise was proportionally lower, such that beam showering resulted in just $0.05^{\circ} \mathrm{C}$ of temperature change.

The cold trap was in operation and the column vacuum was $1-1.3 \times 10^{-5} \mathrm{~Pa}$ throughout. The area for scanning was selected at low magnification $(150 \mathrm{kx})$ then zoomed in to $1 \mathrm{mx}$ for the duration of the irradiation. Following completion of the scan, the magnification was again reduced to $150 \mathrm{kx}$ and spot mode used to mark the scanned regions with contamination dots to aid identification in energy filtered TEM (EFTEM) mode. The thickness of the carbon deposited by the scan was measured using thickness mapping (10eV) slit on a GIF Quantum in energy filtered TEM (EFTEM) mode. The mean free path for carbon at $200 \mathrm{kV}$ was calculated using the method of lakoubovski et al. (lakoubovskii et al., 2008) as 150nm. This enabled the carbon thickness to be obtained from the thickness maps.

Fig. 1a shows an EFTEM thickness map of one such scan. The outer region of interest (ROI - black square) is the scanned image size at $1 \mathrm{mx}$. The actual area scanned by the beam is larger than the scanned image area due to the over scan of the STEM. The thickness of the central segment of the scanned area (white square) was measured. This avoided thickness variations associated with the leading edge of each raster scan (Fig. 1 a top left). The thickness profile measurement (white rectangle) was carried out perpendicular to the scan direction to avoid the run-on and run-off of the scan, which caused contamination build-up outside the main scan area. The thickness profile (Fig. 1b) was used to measure the step function in thickness compared with the contamination-free environs of the scanned area. The thickness of the film either side of the scanned area was measured and averaged. This was subtracted from the thickness in the centre of the scanned area to yield the contamination thickness. This eliminated the effect of any minor global buildup of contamination during set up at $150 \mathrm{kx}$.

Baking was carried out using a JEOL JEC-4000DS dry pumping station. This turbo-pumped system had a quartz heater below the holder and raised the temperature to about $110 \mathrm{deg} C$. There was no vacuum gauge on the system, but the pressure was probably in the $10^{-3} \mathrm{~Pa}$ range. The plasma cleaner was a JEOL EC-52000IC Ion Cleaner. This uses an air plasma generated with a DC potential of 310V. The specimen is not immersed in the plasma but sits about $1 \mathrm{~cm}$ outside the visible glow discharge. This provides very gentle cleaning conditions. The temperature increase measured at the specimen following $1 \mathrm{hr}$ of plasma cleaning was just $1.1^{\circ} \mathrm{C}$. Cooling was carried out using a JEOL single tilt cooling holder, which allowed samples to be cooled between ambient and liquid nitrogen temperature. UV/ozone exposure was carried out in a Bioforce Nanosciences UV/Ozone Procleaner. This uses a UV A light source to generate ozone. This system is a generic surface cleaner and is not specifically designed for electron microscopy specimens. Specimens were placed on a pre-cleaned slide and inserted into the device. The light-source to specimen distance was approximately $15 \mathrm{~mm}$.

3. Results and Discussion

3.1 The effect of magnification 
Microscopists understand that contamination rates generally increase with both probe current and magnification. The critical factor is the local electron flux. Fig. 2 shows the effect of magnification on the measured contamination thickness on a commercial carbon support film for a given scan duration (2mins) with a $0.155 \mathrm{nA}$ probe. It is very clear that the contamination thickness increases with magnification. Increasing the magnification by a factor of five $(1 \mathrm{mx}$ to $5 \mathrm{mx})$ results in a ten-fold increase in the amount of contamination deposited. STEM investigations on non-corrected microscopes might typically work in $<1 \mathrm{mx}$ magnification regime, whereas with aberration-corrected STEM, atomic resolution is generally explored at $>5 \mathrm{mx}$ magnification. Thus a potentially manageable contamination rate at $1 \mathrm{mx}$ of $10 \mathrm{~nm}$ over 2 minutes becomes an intolerable $120 \mathrm{~nm}$ at $5 \mathrm{mx}$. It is interesting to note that the plot of contamination thickness versus magnification is approximately linear. Doubling the magnification would be expected to halve both the $x$ and $y$ dimension of the scanned image, resulting in a reduction of the scanned area by a factor of four, and a corresponding increase in the electron flux by a similar factor. However, this inverse squared dependence is not seen in Fig. 2 and Fig. 1a suggests why. The total area scanned by the beam is much larger than area being imaged. The beam underscans (top left of Fig. 1a) and the various staged approaches of the beam to the actual imaging area are evident as a series of bands, parallel to the leftmost edge of the scanned image. There is a significant build-up in contamination to the left of scanned image area, where the beam dwells while waiting for synchronisation with mains frequency. The result of this is that significant deposition takes place over an area almost twice that of the area imaged being imaged in STEM. The area scanned by the beam is therefore not a simple inverse square function of the magnification.

\subsection{The kinetics of deposition}

Fig. 3 shows a plot of contamination thickness versus the square root of time for a commercial carbon support film (deliberately contaminated with acetone). The linear plot corresponds to a parabolic rate relationship of the type:

$$
\text { Contamination thickness }=\mathrm{K}_{\mathrm{p}} \mathrm{t}^{0.5}+\mathrm{C} \quad \text { eqn (1) }
$$

$\mathrm{K}_{\mathrm{p}}$ is the parabolic rate constant, $\mathrm{t}$ is time and $\mathrm{c}$ is a constant. Such kinetics are typical of a diffusion-limited process and indicate that for a given scanning regime, the rate of contamination is a function of diffusion of hydrocarbons across the specimen to the landing point of the beam (Rykaczewski et al., 2008). The parabolic rate constant is a convenient way of comparing relative contamination rates. In general the fit of the measured data reported here to the parabolic plot was good $\left(R^{2}>0.96\right)$. The c constant varied. In most cases the value was not zero but passed through the $\mathrm{Vt}$ axis at around 5 . This corresponded to an incubation period of around $25 \mathrm{~s}$ during which the contamination rate was low. This is often seen experimentally, where it may be possible to move to a fresh region and capture an image successfully, if done immediately. However, after a short time, contamination commences in earnest. The origin of this incubation period may be associated with the establishment of steady state thermal, electric and chemical potential conditions necessary for establishing a hydrocarbon diffusion gradient. This incubation period is not considered further here.

3.3 The effect of probe current. 
Fig. 4 shows the effect of probe current on the parabolic rate constant for contamination. The rate constant increases with increasing current initially. The peak value corresponds to a probe current of $0.155 \mathrm{nA}$, which is the standard measurement probe used here. The increase in the rate constant with current is not linear but rolls off. A similar shaped curve has been reported by Ennos (Ennos, 1953). At higher currents the trend reverses and the contamination rate begins to fall with further increases in current.

A clue to understanding this behaviour can be seen when observing at the shadow image of the probe (Ronchigram) when correcting STEM alignment on this specimen. At low currents the probed regions are rapidly contaminated and the specimen must be continually moved to a fresh region in order to see the features necessary for alignment. At the higher probe currents the region immediately surrounding the probe region contaminates. However, this does not migrate into the central region of high electron flux. Extended exposure of the thin carbon film to a static probe leads to erosion and eventually a hole is created in the carbon support film. Increasing the electron flux may enhance both hydrocarbon diffusion and cracking rates (Ennos, 1953). However, at higher electron fluxes, new processes come into play. These include beam-induced erosion and sputtering (Egerton and Rossouw, 1976). Beam heating effects are quite minor (Egerton et al., 2004). In the case shown here, contamination is most severe when using the standard measurement probe $(0.155 \mathrm{nA})$. According to Fig. 4 , contamination can be effectively reduced, by up to $50 \%$, by either decreasing or increasing the probe current. The smallest probe used here $(9 \mathrm{C} 5 \mathrm{pA})$, is only useful for high resolution imaging, and is not suitable for microanalysis. In contrast, the largest probe used here ( 3 C $0.498 \mathrm{nA})$ will produce a very high $\mathrm{x}$-ray yield (ca 20kcps for a typical specimen). It is also still sufficiently small to permit atomic resolution $(0.144 \mathrm{~nm})$. The major disadvantage of using such an intense probe is the potential for radiation damage.

\subsection{The effect of baking}

By raising the temperature of the specimen in vacuo to $110^{\circ} \mathrm{C}$, any species with a significant vapour pressure at this temperature should be desorbed (Ennos, 1953; McGilvery et al., 2012). This would include water and light organic fractions such as solvent residue. This technique was applied to commercial nonholey carbon films. These were found to be heavily contaminated in the as-supplied condition, suggesting some issues during manufacture. Commercial support films are relatively inexpensive, and it would normally be most cost effective to simply discard them. However, for the purposes of understanding cleaning procedures processing was carried out.

Fig. 5 shows the measured parabolic rate constants from a series of experiments. Typical errors in the measured slope of kinetic plots were less than $5 \%$. In the first instance (Fig. 5a), the non-holey carbon films were baked for various times in the pumping station. The station was in its original (as-installed) condition, and had been evacuated for many days prior to use. Rather paradoxically, the contamination on the film was found to increase with baking time, rather than decrease. Following a 180 minute bake the contamination rate constant more than doubled from 4.2 to $9.7 \mathrm{~nm} \cdot \mathrm{s}^{-0.5}$. It was believed that this arose due to contamination being mobilised from the walls of the pumping station. With extended baking, the walls of the chamber become warm, and thus might liberate adsorbed species. To confirm this, a contaminationfree specimen was required. In a second series of experiments an ion milled silicon thin foil was plasma cleaned for one hour. This specimen was found to be completely contamination-free when subjected to 16 mins scanning in the microscope $\left(\mathrm{K}_{\mathrm{p}}=0 \mathrm{~nm} \cdot \mathrm{s}^{-0.5}\right)$. It was then transferred to the pumping station and 
baked for 180mins, whereupon it was found to contaminate in the microscope quite significantly $\left(\mathrm{K}_{\mathrm{p}}=3.0\right.$ $\mathrm{nm} . \mathrm{s}^{-0.5}$ ) (Fig. 5b). This confirmed that the pumping station was indeed contributing to the contamination.

In a third series of experiments, efforts were made to decontaminate the pumping station. This entailed heating the station walls to a temperature much higher than might be reached during normal baking whilst continuously evacuating the system. A hot air gun on a retort stand proved to be a very effective heater. To understand the progress of the decontamination, plasma cleaned (1hr) silicon foils were used as the clean reference. Freshly cleaned foils were baked in the pumping station (for $3 \mathrm{hrs}$ ) following station cleaning by 24 and $48 \mathrm{hrs}$ of continuous heating and evacuation. Fig. $5 \mathrm{c}$ shows that the rate constant for contamination was $3.0 \mathrm{~nm} . \mathrm{s}^{-0.5}$ when using the station in the as-received condition. After $24 \mathrm{hrs}$ of heating the station, the rate more than halved to $1.2 \mathrm{~nm} . \mathrm{s}^{-0.5}$, and after a further $24 \mathrm{hrs}$ of heating the rate was zero. Clearly the walls of the pumping station are considerably colder than specimen during baking, and species can strongly adsorb - only to be subsequently liberated during extending baking as the wall temperature rises. Where stations of this type are to be regularly used for baking, then they should be thoroughly cleaned beforehand and probably given a periodic heating treatment to maintain cleanliness.

The fourth series of experiments (Fig. 5d) was a repeat of the initial set (Fig. 5a) using contaminated carbon films, except that the pumping station had been cleaned and it had been confirmed that it was no longer contributing to the measured contamination. Fig. $5 \mathrm{~d}$ shows that within error, there is very little change to the net contamination rate as a function of baking time, and that baking does not remove the hydrocarbon residue from these specimens. This is perhaps not unexpected, in that the specimens were contaminated during manufacture - quite possibly by diffusion pump oil. These oils typically have extremely highly boiling points (ca $450 \operatorname{deg} C$ ) and so at the baking temperature of $110 \operatorname{deg} C$ the vapour pressure of such species is negligible.

Fig. 6a shows parabolic rate constants obtained from a carbon support film on which PbS quantum dots had been dispersed. The chemical synthesis method employed methanol and thiolactic acid (TLA). These have boiling points of 64.7 and $102 \mathrm{deg} C$ respectively. In the as-dispersed condition, significant contamination was present, such that atomic resolution imaging was impossible to set up, before the contrast was obliterated. The measured $\mathrm{K}_{\mathrm{p}}$ value (Fig. $6 \mathrm{a}$ ) in the as-dispersed condition was $8.9 \mathrm{~nm} . \mathrm{s}^{-0.5}$. Following $180 \mathrm{mins}$ baking this reduced to $2.8 \mathrm{~nm} . \mathrm{s}^{-0.5}$. A further $150 \mathrm{mins}$ baking produced only a small improvement to $2.4 \mathrm{~nm} . \mathrm{s}^{-0.5}$. A factor of three reduction in the rate constant is significant. This result demonstrates that baking can be effective. However, it only works when dealing with adsorbed species which have relatively high vapour pressures at the baking temperature. The very minor improvement between 180 and 330mins suggests that further baking will offer little further improvement. Even in the baked condition, contamination was still an issue. A $K_{p}$ value of around $3 \mathrm{~nm} . \mathrm{s}^{-0.5}$ results in approximately $20 \mathrm{~nm}$ of contamination build-up within 60 s of scanning at $1 \mathrm{mx}$. Further contamination mitigation, such as beam showering (see later), is certainly required. However, the removal of the bulk of the contaminants by baking, means that subsequent processing steps can be of shorter duration and/or of lower intensity. Baking schedules of up to perhaps $12 \mathrm{hrs}$ may be used, but several hours of cooling time should also be allowed, to minimise thermal drift effects, when the holder is subsequently inserted into the microscope. It is clear that baking is a relatively slow process, is better suited to overnight treatments and will only be effective where potential contaminants have boiling points close the baking temperature.

The main focus of this work has been on minimising carbon contamination. However, other contaminants can also be troublesome, especially when doing $x$-ray microanalysis. Fig. $6 \mathrm{~b}$ shows energy dispersive $\mathrm{x}$-ray 
spectra (EDS) obtained from a NiO thin film on a Mo grid. This commercially-sourced reference film is useful for quantifying the performance of EDS systems and for diffraction and other microscope calibrations (Egerton and Cheng, 1994). In this case, in the as-received condition, silicon contamination was apparent in the EDS spectrum and circular contamination marks were evident surrounding the $200 \mathrm{~nm}$ diameter regions probed in TEM mode. Following baking for $1 \mathrm{hr}$, the contaminating silicon peak was removed completely. All evidence for contamination build-up also disappeared after the baking. It seems likely that this film became contaminated by some kind of silicone. Contaminant layers cannot be tolerated on this specimen as they affect the carbon and oxygen x-ray intensities (Fig. 6b), which are used to determine the presence (if any) of ice and hydrocarbon films on the EDS detector crystal (Egerton and Cheng, 1994).

\subsection{The effect of cooling}

Since the contamination process typically involves the diffusion of hydrocarbons, the diffusion rate will be an exponential function of temperature (Rykaczewski et al., 2007), as described by the Arrhenius relationship. Cooling the sample should therefore slow the migration of species dramatically (Egerton and Rossouw, 1976). The contamination rate of an acetone-contaminated carbon support was measured as a function of temperature from $20^{\circ} \mathrm{C}$ to $-0.3^{\circ} \mathrm{C}$ in roughly $5^{\circ} \mathrm{C}$ increments (Fig. 7). The rate constant was found to be very sensitive to temperature, decreasing by over an order of magnitude over this temperature range. At the lowest temperature measured $\left(-0.3^{\circ} \mathrm{C}\right)$ the rate constant was just $0.54 \mathrm{~nm} \cdot \mathrm{s}^{-0.5}$. This is a very low rate of contamination, corresponding to just $4 \mathrm{~nm}$ of deposit during a $60 \mathrm{~s}$ scan. Lower temperatures were not investigated, due to the difficulty of measuring rates below this value. The Arrhenius plot is shown in Fig. 7 and indicates an activation energy for diffusion of 76kJ.mol-1. This behaviour and the parabolic kinetics is confirmation that contamination involves thermally activated diffusion of hydrocarbons across the surface of the specimen. Activation energies reported for diffusion of hydrocarbons in activated carbon, show that the energies vary significantly with molecular weight and polarity (Do D. D, 2001). Values of 40, 44 and 53kJ.mol-1 were reported for $n$-hexane, Benzene and Ethanol respectively. The nature of the hydrocarbon residues encountered in this work are unknown, but from their low volatility and high activation energy for diffusion, may include long chain hydrocarbons, aromatics and/or plasticisers, for which acetone is such a good solvent.

No deposition from the vacuum (other than ice) has been observed at liquid nitrogen temperature. Film loss due to sputtering or oxidation from oxygen-containing contaminants in the vacuum has been observed (Egerton and Rossouw, 1976; Griffiths A. J. V., 2010), but under the very high vacuum and scanning beam conditions used here, none was observed. The activation energy for surface diffusion measured here is high, with the rate decreasing ten fold for a $20^{\circ} \mathrm{C}$ decrease in temperature. Fig. 7 permits the influence of lower temperatures on the contamination rate to be predicted. For example, at $-20^{\circ} \mathrm{C}$ the rate would be negligibly low ( $\mathrm{Kp}=0.04 \mathrm{~nm} . \mathrm{s}^{-0.5}$ ) equivalent to just $0.3 \mathrm{~nm}$ of contamination forming in $60 \mathrm{~s}$ of scanning. Cooling to $-196^{\circ} \mathrm{C}$ is therefore far colder than is necessary to effectively stop contamination. However, the thermal stability, vibration (due to boil off) and consumption rate of liquid nitrogen by the cooling holder are all greatly improved by allowing it to stabilize at liquid nitrogen temperature. The specimen's tolerance to damage is also improved.

A nanoparticulate dispersion of PtNi was used to assess the experimental effectiveness of cooling. The specimen was synthesised using oleylamine as a surfactant. This long chain hydrocarbon has a very high boiling point ( $b p=364$ deg $C$ ). TEM specimens were made by ultrasonically dispersing the material in $n$ - 
nexane ( $b p=68 \mathrm{deg} C)$. The initial $\mathrm{K}_{\mathrm{p}}$ value was $11.5 \mathrm{~nm} \cdot \mathrm{s}^{-0.5}$. Baking this specimen for up to $630 \mathrm{mins}$ in vacuo, reduced this rate constant only marginally to $10.3 \mathrm{~nm} \cdot \mathrm{s}^{-0.5}$. Given the low vapour pressure of oleylamine at the baking temperature, this was not unexpected. Fig. 8a shows a thickness map from a $1 \mathrm{~min}$ scan on the specimen after baking. The very intense spot is a mark added after the scan to aid identification for thickness mapping. The contamination rate within the scanned area is higher in close proximity to clusters of particles, which act as reservoirs for hydrocarbons. In part, contamination can be minimised by avoiding the larger clusters of particles on the film and imaging only the smallest isolated clusters/individual particles. The effect of cooling on the contamination rate is shown in Fig. $8 \mathrm{~b}$. The measured $\mathrm{K}_{\mathrm{p}}$ value on the carbon film (away from any clusters) at room temperature was $10.3 \mathrm{~nm} \cdot \mathrm{s}^{-0.5}$. This corresponded to over $70 \mathrm{~nm}$ of contamination forming during just $60 \mathrm{~s}$ of scanning at $1 \mathrm{mx}$ - rendering it impossible to image. Following cooling to liquid nitrogen temperature all hydrocarbon contamination stopped ( $\left.\mathrm{Kp}=0 \mathrm{~nm} \cdot \mathrm{s}^{-0.5}\right)$, regardless of proximity to PtNi clusters. No loss in thickness, due to beam-induced erosion, was noted. Although some ice did form on unirradiated regions, this was removed within seconds of exposing it to the beam. Scissioned water, from such ice can give rise to active oxygen, which can oxidise the film. However, no evidence for this was seen here.

Cooling the specimen to liquid nitrogen temperature is therefore an exceptionally effective method for completely stopping hydrocarbon contamination. Metallic particles such as these are very resistant to electron beam damage, but in electron beam sensitive materials such ionic crystals, hydrated phases, polymers etc, cooling can dramatically reduce the effect of electron beam damage (Egerton et al., 2004). It is also very useful for minimising electron beam reduction when using electron energy loss spectroscopy to determine valence state (Colella et al., 2005). Cooling is not a rapid process and typically, one hour is added to both the start and end of each experiment, to allow for cool-down and warm-up of the specimen holder. Also, the general stability and attainable resolution of cooling holders is inferior compared with that of room temperature equivalents.

\subsection{The effect of plasma cleaning}

Plasma cleaning has been used for many years as a means of either immobilising hydrocarbons or removing them (Griffiths A. J. V., 2010; Isabell et al., 1999; McGilvery et al., 2012; Zaluzec, 2001; Zaluzec et al., 1997). Inert plasmas based on argon have been shown to prevent new contamination forming. However, such plasmas will not remove previously deposited carbon (Zaluzec et al., 1997). Plasmas containing oxidising species have been shown to be very effective at removing both hydrocarbons and any previously deposited carbon contamination. Air, pure oxygen, oxygen/argon and oxygen/hydrogen mixtures have all been used. One major limitation with plasma cleaning is the potential to damage carbon support films and carboncontaining specimens. Also, where valence state is being studied, oxidation may occur.

The JEOL plasma cleaner used in these studies uses a DC voltage (310V) to form a low power air plasma. The specimen is not immersed in the visible glow discharge, but is located approximately $1 \mathrm{~cm}$ outside of it. It therefore provides a very gentle clean. The rate of oxidation of carbon support films in this system was determined by exposing a clean lacey carbon film to standard plasma cleaning conditions for various durations and measuring the thickness of the same region of film. The removal rate was found to be a linear function of time and occurred at a rate of approximately $5 \mathrm{~nm} . \mathrm{hr}^{-1}$. No visible deterioration of the support film was evident after $2 \mathrm{hrs}$ of plasma cleaning, and so specimens of this type can be readily cleaned with this system without unduly damaging the support. This removal rate is a useful parameter to know, 
since it allows the controlled thinning of support films. The thinning rate will be very specific to the model of cleaner and experimental conditions used, and so should be determined for each cleaning setup.

Fig. 9a shows the contamination rate constants for commercially bought carbon supports which were contaminated during manufacture. Baking this film for up to $270 \mathrm{mins}$ (Fig. $5 \mathrm{~d}$ ) was ineffective. Plasma cleaning for as short as $1 \mathrm{~min}$ removed much of the contamination, with the rate constant reducing from 9.7 to $3.7 \mathrm{~nm} \cdot \mathrm{s}^{-0.5}$. However, extended cleaning for up to 121 minutes lowered the rate only very slightly (3.0 $\left.\mathrm{nm} \cdot \mathrm{s}^{-0.5}\right)$.

A very different result was obtained with a sputtered gold on carbon specimen. This is a standard specimen provided to carry out tuning of the aberration corrector. Typically this specimen is imaged at $400 \mathrm{kx}$ to $600 \mathrm{kx}$ during corrector tuning, and contamination results in poor tuning performance. As delivered, this specimen contaminated very badly $\left(K_{p}=12.9 \mathrm{~nm} . \mathrm{s}^{-0.5}\right)$, and baking the specimen at $110 \mathrm{deg} C$ for 12 hours did not result in any significant improvement. In contrast, $1 \mathrm{hr}$ of plasma cleaning completely removed the fairly significant contamination (Fig. 9b). No discernible damage occurred to the film, which despite having a very thin carbon support of perhaps $20-30 \mathrm{~nm}$, did not tear or pinhole during cleaning.

The contrast between the plasma cleaning behaviour of the carbon support film (Fig. 9a) and the sputtered gold on carbon (Fig. 9b) was quite marked. The gold on carbon was completely decontaminated following $1 \mathrm{hr}$ of cleaning, whereas the plain carbon film, which had a slightly lower initial contamination rate, was still contaminated after $2 \mathrm{hrs}$ of cleaning. The nature of the hydrocarbons on both films was probably quite similar - since both were resistant to baking. The gold nanoparticles may exert catalytic effects and/or secondary electrons may enhance hydrocarbon elimination.

Ion polished foils of silicon are fully dense and typically offer few niches in which hydrocarbons might elude the effects of the plasma. In the as-milled condition, the foil was found to be very clean, such that after 4 minutes of standard scanning with an analytical probe at $1 \mathrm{mx}$ only the faintest trace of contamination was evident (not shown). Low voltage milling $(<500 \mathrm{eV})$ is very effective final polishing step to remove amorphous/oxide and beam-damaged layers(Mehrtens et al., 2012). Due to the very low rates of material removal, and the minimal induced-radiation damage, the method can also be used for cleaning contaminating bulk specimens. The conventional lon mill $(5-3.5 \mathrm{kV})$ used here was unable to operate effectively at such low energies, and so the effect of low energy milling has not been investigated here.

The very low rates of contamination on the silicon foil precluded the use of the standard contamination measurement procedure. However, during atomic resolution imaging at $20 \mathrm{mx}$, contamination was very noticeable. The thickness of contamination deposits developed during $30 \mathrm{~s}$ of scanning at $20 \mathrm{mx}$ were therefore measured and used for comparison. Fig. 10a shows a thickness map of a cross-section of a memory (DRAM) chip in the as-ion milled condition. The bright horizontal stripe is a tungsten-containing part of the device. This region has much shorter mean free path than the surrounding silicon, resulting in higher local intensity compared with the surrounding silicon. The three contamination spots arose from 30s scans at $20 \mathrm{mx}$. It is clear that contamination is greatest nearest the device interface and decreases with distance from it. Differential milling effects can create crevices at such interfaces which aid hydrocarbon retention. Fig. 10b shows that the contamination thickness decreases exponentially with plasma cleaning time and can be completely eliminated by plasma cleaning for 60 mins. In this condition, it was possible to obtain a lattice image of silicon (Fig. 10c inset) and preserve the lattice contrast throughout a $16 \mathrm{~min}$ scan (analytical probe of $0.155 \mathrm{nA}$ ). Not only was lattice resolution preserved throughout the scan, but no 
contamination mark was apparent when the region was examined at lower magnification (Fig. 10c). No contamination at the interfaces between structures was found either (not shown).

Plasma cleaning is therefore highly effective at completely removing hydrocarbons from sputtered gold on carbon films and ion milled silicon foils. With the very gentle plasma cleaner used here, contamination could be completely removed in $1 \mathrm{hr}$, with no detrimental effect on carbon support films. However, even after $2 \mathrm{hrs}$ of cleaning a commercial carbon film, contamination could not be removed completely. McGilvery et al. (McGilvery et al., 2012) also noted that plain carbon films could not be completely cleaned of contamination using plasma cleaning. Higher power cleaners or those using oxygen-based plasmas may operate more rapidly that that used here, although great care in their use during cleaning of carbon support films or oxidation sensitive phases will be necessary.

\subsection{The effect of beam showering}

Beam showering irradiates a very large area of specimen with a high electron flux so that hydrocarbons which might otherwise migrate are cracked and form an extremely thin layer of immobile carbon. This showered area can then be examined in detail without contamination occurring, at least in the short-term. The showered area forms a cordon sanitaire around the area of interest. However, hydrocarbons will migrate across this region, and contamination may begin to reoccur after an interval, which will be shorter for more heavily contaminated specimens.

Since beam showering results in thin contamination layers forming, it is not a preferred first form at attack. Other methods should be used to remove the bulk of the contamination. Beam showering should then be used to mop up any residual contamination. There are no standardised conditions for beam showering, and every operator has his or her preferred recipe. The procedure used here entailed: scanning the beam, setting the magnification to the bottom of the normal STEM magnification range (20kx); underfocusing the beam such that no microstructural features were evident; retracting the HAADF detector and lowering the fluorescent screen to protect the STEM detectors; inserting a small SA aperture to protect the fluorescent screen; retracting the $\mathrm{C} 2$ beam limiting condenser aperture (40ums) but leaving the largest $\mathrm{C} 1$ aperture inserted (150ums); setting the spot size to $1 \mathrm{C}$ (largest) and finally de-exciting the CL1 lens using the free lens control to a hexadecimal value of 6300 (to almost double the beam current). Showering times of anywhere between 5 and 20 minutes can be used. This condition produced a probe current of $23.3 \mathrm{nA}$. Table 2 summarises the various probe and electron flux conditions resulting from the various imaging modes used here.

For a given probe current, the electron flux during atomic resolution STEM imaging at $20 \mathrm{mx}$ is increased by a factor of 400 compared with that of the Measurement Scan of $1 \mathrm{mx}$, due to the corresponding reduction in scan area (ignoring the effects of STEM overscan and line-synch dwells). During beam showering both scanned area and probe current are changed. Compared with the Measurement Scan at $1 \mathrm{mx}$, beam showering at $20 \mathrm{kx}$ results in a 2500 fold reduction in scan area. This is only partially offset by the two orders of magnitude increase in current produced by aperture, spot size and CL1 lens changes. The beam showering electron flux $\left(2.0 \times 10^{3} \mathrm{~nm}^{-2} \mathrm{~s}^{-1}\right)$ is therefore an order of magnitude lower than that during the Measurement Scan at $1 \mathrm{mx}\left(3.3 \times 10^{4} \mathrm{~nm}^{-2} \mathrm{~s}^{-1}\right)$. Nevertheless, in most instances this flux is sufficient to 
eliminate mild contamination completely, even when carried out for relatively short intervals (5-10mins). In instances where this is not the case, the option to remove the 150um condenser aperture can be used. This increases the probe current by a factor of 6 to $153.4 \mathrm{nA}$, producing a comparable electron flux $\left(1.3 \times 10^{4} \mathrm{~nm}\right.$ $\left.{ }^{2} \mathrm{~s}^{-1}\right)$ to that of the Measurement Scan $\left(3.3 \times 10^{4} \mathrm{~nm}^{-2} \mathrm{~s}^{-1}\right)$.

As discussed earlier, baking the PtNi nanoparticulate dispersed on holey carbon was completely ineffective at removing oleylamine and other residues (Fig. 8a). The rate constant for contamination $\left(\mathrm{K}_{\mathrm{p}}=11.5 \mathrm{~nm} . \mathrm{s}^{-0.5}\right)$ changed very little after baking for up to $630 \mathrm{mins}\left(\mathrm{K}_{\mathrm{p}}=10.3 \mathrm{~nm} \cdot \mathrm{s}^{-0.5}\right)$. Plasma cleaning this specimen did not generally provide much benefit. Beam showering for ten minutes completely eliminated contamination, such that parking a static beam parked in one location for several minutes, did not result in any discernible contamination mark. Clustered nanoparticulate specimens create partially closed spaces between individual particles and between particles and the carbon support film. These regions act as reservoirs for hydrocarbon contamination (Fig. 8a), and are sheltered from the effects of oxidising species in the plasma. However, during beam showering high energy electrons penetrate these regions and can act directly on hydrocarbons therein. In addition, the interaction of the beam with the nanoparticulates produces very high local fluxes of secondary electrons. These interact strongly with organic species, causing them to be immobilised (Egerton et al., 2004). The area of the beam shower corresponds to about one grid square on a typical TEM support gird. Only the area directly showered is decontaminated, since moving to an adjacent grid square resulted in an immediate return of the contamination. Although beam showering is rapid, it must be carried out on each unshowered region of specimen examined.

Excellent results were also obtained when beam showering the $\mathrm{PbS}$ quantum dot specimen. Baking for up to 330 mins resulted in a 3 fold reduction in contamination rate (Fig. 6a). However, the $K_{p}$ value $\left(2.4 \mathrm{~nm} . \mathrm{s}^{-0.5}\right.$ ) was still sufficiently high to result in $20 \mathrm{~nm}$ of contamination build-up during a 60 s interval (a time-frame typically used for focusing and imaging). Beam showering for just 5 mins completely eliminated the contamination problem.

Fig. $10 \mathrm{~b}$ shows the contamination thicknesses ( $30 \mathrm{~s}$ scan at $20 \mathrm{mx}$ ) formed on silicon as a function of plasma cleaning time. Contamination was still significant after $10 \mathrm{mins}$ of plasma cleaning with $22.5 \mathrm{~nm}$ of carbon deposited within a 30s scan. Beam showering for 5 mins eliminated contamination completely from a subsequent 30s scan at $20 \mathrm{mx}$. However, following extending scanning ( $5 \mathrm{mins}$ ) the contamination reappeared (thickness $=6 \mathrm{~nm}$ ). Most likely due to migration of contamination across the showered region. The great advantage of beam showering is that it can immobilise any type of hydrocarbon species, regardless of volatility. It can be carried in-situ on the region of interest and generally is quite rapid. For specimens comprising heavy elements, the high secondary electron yield enhances the effects of showering and even heavily contaminating films can be made completely contamination-free using beam showers of just 5 mins. In the case of monolithic specimens of lower atomic number, and thus lower secondary electron yield, longer beam showers of 10-15mins may be required to eliminate the problem.

In-situ processing avoids time lost during sample removal and transfer to, for example a plasma cleaner. On the basis of the equipment used here, beam showering is the fastest method of eliminating contamination. The major disadvantage of beam showering is that of beam damage to sensitive materials such as polymers, ionic crystals, hydrated species etc. For such materials, cooling is the best approach as it will both eliminate contamination and make the specimen considerably more resistant to beam damage. 


\subsection{The effect of UV/ozone cleaning}

Short wavelength ultra-violet light (UV A) and ozone have been used to remove hydrocarbons from surfaces, and a commercial system designed for TEM specimen cleaning is available (Hoyle et al., 2011). We do not have access to such a TEM specimen cleaner, but instead used a Bioforce Nanosciences UV/Ozone Procleaner system. This is designed ostensibly for removing molecular contaminants from bulk surfaces. A clean carbon support film on a copper grid was contaminated with a drop of acetone and allowed to dry. The contamination rate was measured as $K_{p}=3.9 n m . s^{-0.5}$. The grid was then placed on a cleaned glass slide and inserted into the UV cleaner. It was exposed to intense UV and ozone for $80 \mathrm{mins}$. The subsequently measured rate constant was lower by about $30 \%\left(K_{p}=2.7 \mathrm{~nm} \cdot \mathrm{s}^{-0.5}\right)$. Removal rates reported for a system specifically designed for TEM specimen cleaning are somewhat higher. In a similar fashion to plasma cleaners, they produce an initially high removal rate, resulting a 50\% reduction after 5 mins cleaning, but a much slower rate of removal thereafter (Soong et al., 2012).

\subsection{The effect of microscope air lock pumping time}

Over the years conflicting advice from microscope vendors has been provided regarding the amount of time the specimen holder should be pumped in the airlock prior to insertion into the column. Extended pumping will allow volatile residues on/in the specimen/holder, such as water vapour and solvents, to be pumped away prior to admission into the column. However, this may allow back-streaming oil from the pumping system or other airlock contaminants to compromise the specimen. Very short pumping times will result in the specimen outgassing in the column, with the potential to degrade the vacuum and shorten the life of the ion pump. To assess the impact of pumping time, a silicon foil which had been air plasma cleaned for $1 \mathrm{hr}$ was used as a clean reference specimen. This specimen was plasma cleaned and then inserted into the column using the minimum amount of pumping time necessary to obtain an airlock ready light (about 3 mins). The contamination rate was measured using the standard Measurement Scan at $1 \mathrm{mx}$, and no contamination was recorded after 16 mins scanning. This process was repeated using increasingly longer air lock pump down times $(5,10$ and $60 \mathrm{mins})$. Only after a total of $60 \mathrm{mins}$ in the airlock was contamination observed, albeit relatively minor $\left(K_{p}=0.7 n m \cdot s^{-0.5}\right)$.

A pumping time of 60mins is clearly much longer than is ever necessary. Pump down time is very much specimen/holder dependent. A fully dense specimen in a holder which has only just been removed from the airlock (or a pumping station), may be ready for insertion after only 3 mins of pumping. Where the holder/airlock have been left exposed to atmosphere for an extended period, or when examining a specimen with very large surface area, such as a highly porous catalyst support, then pumping times of 5 to 10 mins may be necessary. As this is a new microscope the airlock is therefore very clean. Much shorter contamination-free pump down periods may prevail in older microscopes, as with use, the airlock can become increasingly contaminated. The plasma cleaned Silicon foil method used here is a good way of assessing the ongoing performance of airlock, and may indicate when airlock cleaning may be required

On the system used here, the conditions for holder insertion include: vacuum ready light on and an airlock pressure (Pirani gauge) which is within $4 \mathrm{~mA}$ of base pressure. Most important is the pressure of the reservoir tank. This is a buffer tank between the rotary pump and the airlock diffusion pump. This tank is continuously pumped by a rotary pump, and its pressure is very sensitive to the amount of vapour the diffusion pump is moving. Only when this pressure is also within $4 \mathrm{~mA}$ of base pressure, is the holder 
inserted. On this basis, typically evacuation times are about 5 mins. After starting a pump down cycle, the time taken for the reservoir tank to return to base pressure is about 20 mins. The measurements here show that contamination does not occur while the diffusion pump is actively moving vapour out of the airlock. Only once the system reaches base pressure can back-streaming occur. On the basis of these results the optimum pumping for this type of vacuum system (rotary/diffusion/ion pumps) which minimises contamination, maximises workflow and reduces wear and tear on the column ion pump is 5 to $10 \mathrm{mins}$. For strongly outgassing specimens/holders prepumping in a dry pumping station is much preferred over extended use of the (diffusion pumped) microscope air lock.

\section{General Strategy for Specimen Decontamination.}

The overall approach used will depend on the specimen, the nature of the contaminant and the equipment available. Based on the methods assessed here, the following general strategies might be applied:

Bulk Specimens: Semiconductors, metal foils etc. As such materials are fully dense, and may contain adhesive from specimen preparation (eg cross-sectional specimens, tripod polished sections etc) avoid baking. Apply plasma cleaning followed by beam showering if necessary.

Thin films/particulates on support films:

Low volatility residues: (eg heavy surfactants, oils) - plasma clean then beam shower.

Volatile residues: (eg water, light solvents etc) - bake. In the case of significant contamination, plasma cleaning may also help. Finally, beam shower as necessary.

Beam Sensitive Materials: (eg ionic/hydrated crystals, polymers etc) - cooling is universally effective for all types of contaminant.

\section{Conclusions.}

At the very high magnifications and electron fluxes used in atomic resolution aberration-corrected STEM, hydrocarbon contamination can become a critical limitation. Specimen baking can be moderately effective at removing both hydrocarbon and silicon-based contamination. However, it is a slow method, requiring several hours and is best suited to overnight processing. It is only effective for species which have a high vapour pressure at the baking temperature, such as water and light solvent residues. For specimens contaminated with vacuum pump oil, long chain surfactants or other high boiling point materials, it is completely ineffective. A clean pumping station is an essential prerequisite for this type of cleaning operation. The parabolic kinetics observed for contamination indicate a diffusion-controlled reaction. Surface diffusion of hydrocarbons across the specimen is thermally activated and so cooling specimens to liquid nitrogen temperature stops contamination completely. Cooling also has the advantage of making specimens more resistant to electron beam damage. The major disadvantage of cooling is the experimental overhead, which typically adds one hour to the start and end of each experiment. Plasma cleaning with an oxidising (air) plasma removes much of the contamination from specimens within the first few minutes of processing. However, carbon films could not be fully cleaned even after two hours of cleaning. In contrast, gold on carbon and bulk silicon specimens were made completely contamination-free after one hour of 
cleaning. Beam showering is a rapid technique and easily carried out, with showers of 5 to 10 minutes being very effective at arresting contamination for sufficiently long to enable imaging/mapping at the atomic scale $(20 \mathrm{mx})$. However, recontamination can reoccur due to diffusion of hydrocarbons into the field of view from outside of the showered area. The rate and extent of recontamination is a function of the initial contaminant load. Therefore, preliminary decontamination using baking or plasma cleaning can reduce the duration and intensity of subsequent beam showering, or even eliminate the need for it entirely. The major advantage of beam showering is that it is an in-situ technique and can be carried out on the region of interest very rapidly. UV/Ozone cleaning is effective, but with the equipment used here, was very slow compared with plasma cleaning and especially beam showering.

\section{Acknowledgements}

This research was funded by the University of Wollongong and used a JEOL ARM200F facility funded by the Australian Research Council (ARC) - Linkage, Infrastructure, Equipment and Facilities (LIEF) grant LE120100104, located at the UoW Electron Microscopy Centre. Dr M. Nancarrow is thanked for assistance with UV/Ozone cleaning.

\section{References}

Colella, M., Lumpkin, G.R., Zhang, Z., Buck, E.C., Smith, K.L., 2005. Determination of the uranium valence state in the brannerite structure using EELS, XPS, and EDX. Phys Chem Minerals 32, 52-64. Do D. D, D.H.D., 2001. Surface diffusion of hydrocarbons in activated carbon: Comparison between constant molar flow, differential permeation and differential adsorption bed methods. Adsorption 7, 189-202.

Egerton, R.F., Cheng, S.C., 1994. Characterization of an analytical electron microscope with a $\mathrm{NiO}$ test specimen. Ultramicroscopy 55, 43-54.

Egerton, R.F., Li, P., Malac, M., 2004. Radiation damage in the TEM and SEM. Micron 35, 399-409. Egerton, R.F., Rossouw, C.J., 1976. Direct measurement of contamination and etching rates in an electron beam. Journal of Physics D: Applied Physics 9, 659.

Ennos, A.E., 1953. The origin of specimen contamination in the electron microscope. British Journal of Applied Physics 4, 101-106.

Griffiths A. J. V., W.T., 2010. Quantification of carbon contamination under electron beam irradiation in a scanning transmission electron microscope and its suppression by plasma cleaning. Journal of PhysicsL Conference Series 241, 012017-012020.

Hoyle, D., Malac, M., Trudeau, M., Woo, P., 2011. UV Treatment of TEM/STEM Samples for Reduced Hydrocarbon Contamination. Microscopy and Microanalysis 17, 1026-1027.

Hren, J.J., 1986. Barriers to AEM: Contamination and Etching, in: Joy, D., Romig, A., Jr., Goldstein, J. (Eds.), Principles of Analytical Electron Microscopy. Springer US, pp. 353-374. lakoubovskii, K., Mitsuishi, K., Nakayama, Y., Furuya, K., 2008. Thickness measurements with electron energy loss spectroscopy. Microscopy Research and Technique 71, 626-631.

Isabell, T.C., Fischione, P.E., O'Keefe, C., Guruz, M.U., Dravid, V.P., 1999. Plasma Cleaning and Its Applications for Electron Microscopy. Microscopy and Microanalysis 5, 126-135.

McGilvery, C.M., Goode, A.E., Shaffer, M.S.P., McComb, D.W., 2012. Contamination of holey/lacey carbon films in STEM. Micron 43, 450-455.

Mehrtens, T., Bley, S., Venkata Satyam, P., Rosenauer, A., 2012. Optimization of the preparation of GaN-based specimens with low-energy ion milling for (S)TEM. Micron 43, 902-909. 
Rykaczewski, K., Marshall, A., White, W.B., Fedorov, A.G., 2008. Dynamic growth of carbon nanopillars and microrings in electron beam induced dissociation of residual hydrocarbons. Ultramicroscopy 108, 989-992.

Rykaczewski, K., White, W.B., Fedorov, A.G., 2007. Analysis of electron beam induced deposition (EBID) of residual hydrocarbons in electron microscopy. Journal of Applied Physics 101, -.

Schamm, S., Zanchi, G., 2001. Contamination and the quantitative exploitation of EELS low-loss experiments. Ultramicroscopy 88, 211-217.

Soong, C., Hoyle, D., Malac, M., Egerton, R., 2012. The sources of contamination of TEM samples and the means for its reduction. Microscopy and Microanalysis 18, 1480-1481.

Williams, D.B., Carter, C.B., 1996. Transmission Electron Microscopy: A textbook for Materials Science. Plenum Press, New York, 119-124.

Zaluzec, N.J., 2001. Plasma Processing of Specimens for Electron Microscopy \& Microanalysis. Springer-Verlag, Berlin, Heidelberg, New York.

Zaluzec, N.J., Kestel, B.J., Henriks, D., 1997. Reactive gas plasma specimen processing for use in microanalysis and imaging in analytical electron microscopy. Microscopy and Microanalysis 3, 10-14. 


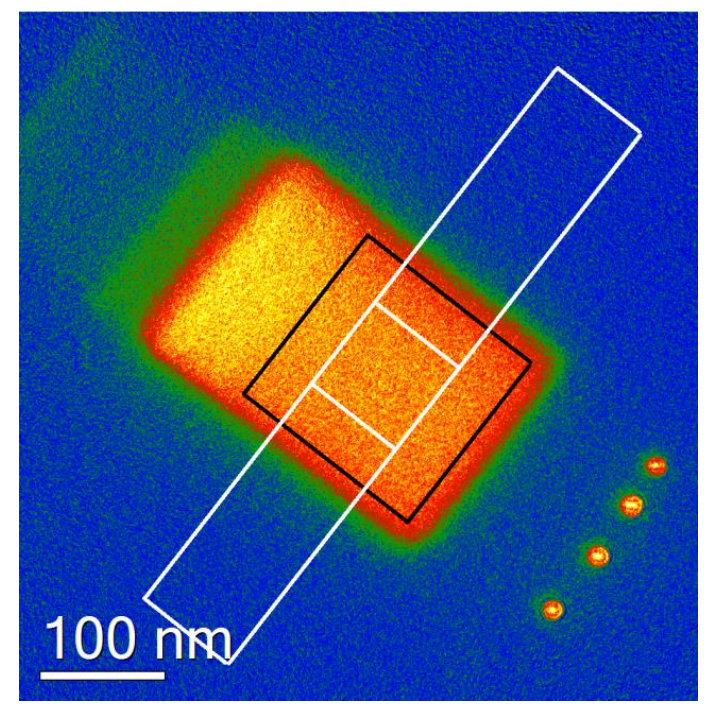

A

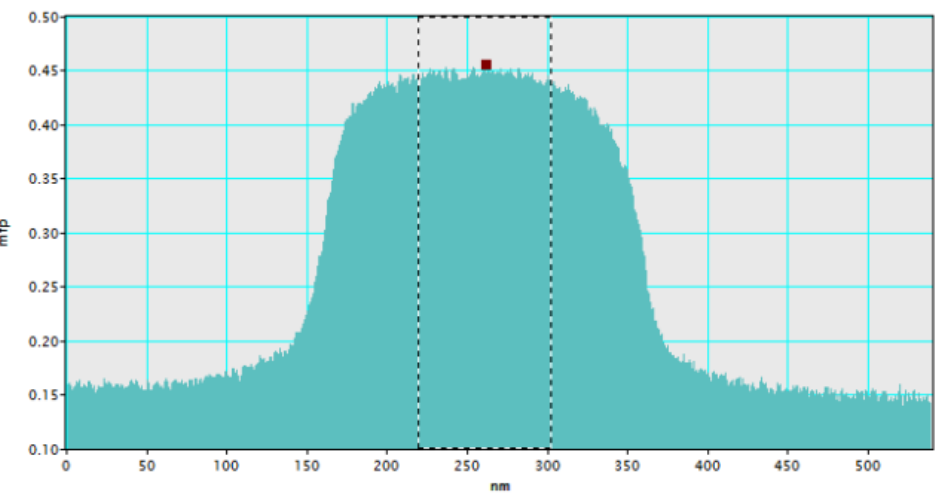

B

Fig. 1. Thickness map showing contamination build-up on a commercial carbon film scanned for $4 \mathrm{mins}$ at $1 \mathrm{mx}$. The black square shows the actual image area at $1 \mathrm{mx}$. The white rectangle shows the position/width of the region sampled for averaging thickness; $b$ ) Thickness profile obtained from the white rectangle in a). Background thickness is obtained by averaging $10 \%$ at each end of the profile. The contamination thickness is measured by averaging the central white square.

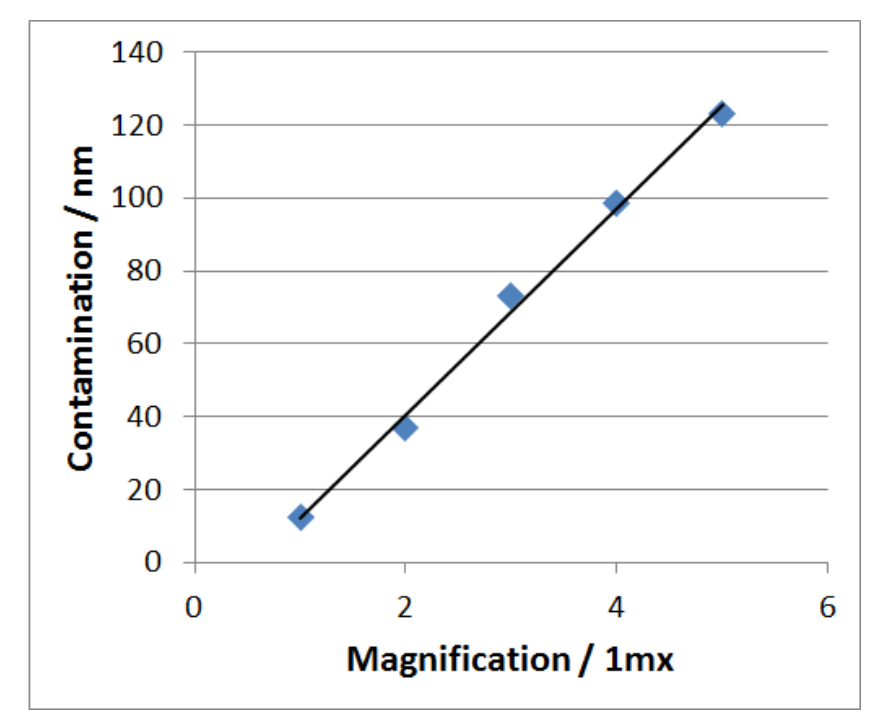

Fig. 2 Carbon contamination thickness ( 2 min scanning on a commercial carbon support film using a $0.155 \mathrm{nA}$ probe) as a function of magnification. 


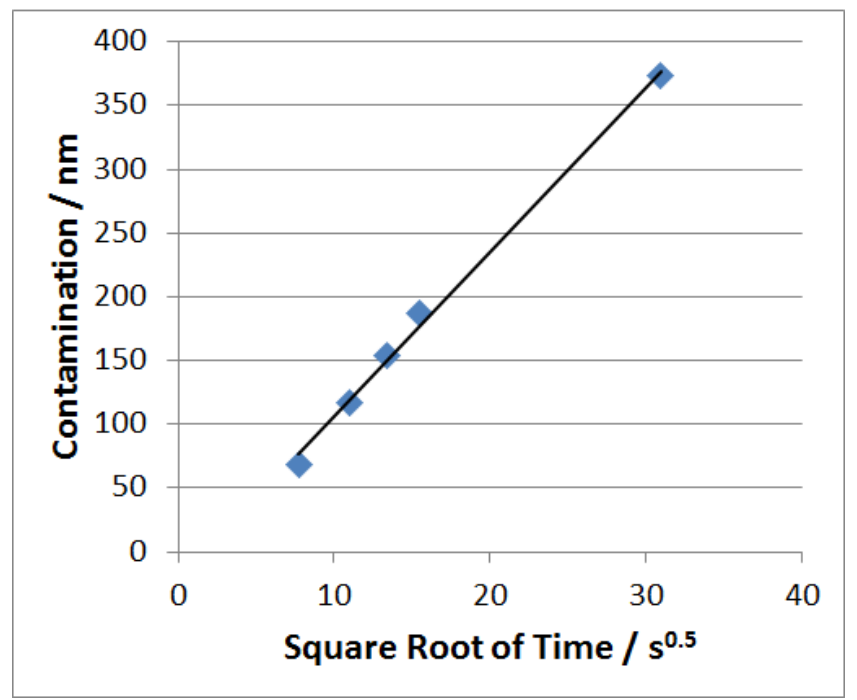

Fig. 3 Contamination thickness formed on an acetone-contaminated commercial carbon film as a function of the square root of scanning time. The slope of the linear fit corresponds to the parabolic rate constant $\left(K_{p}\right)$.

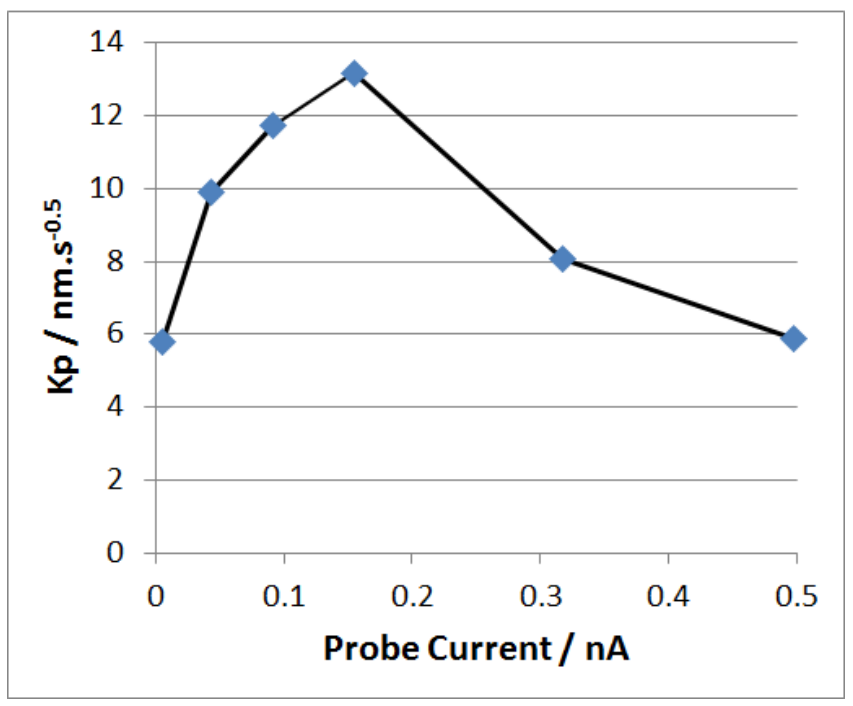

Fig. 4 The effect of probe current on the parabolic rate constant for contamination (carbon film contaminated with acetone). 


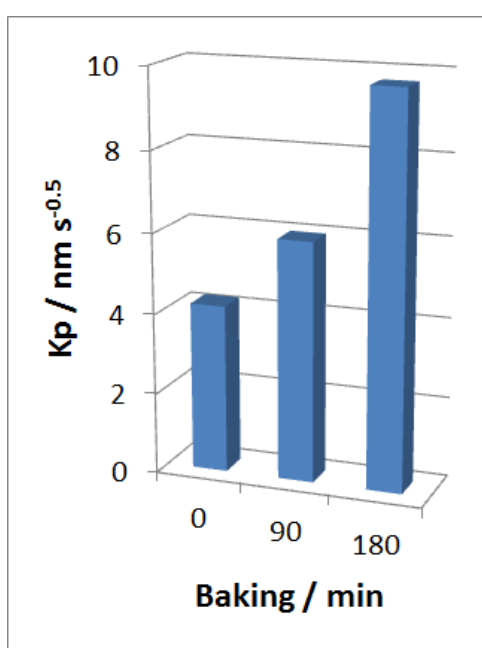

A

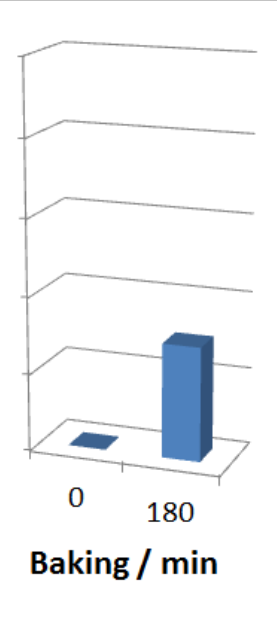

B

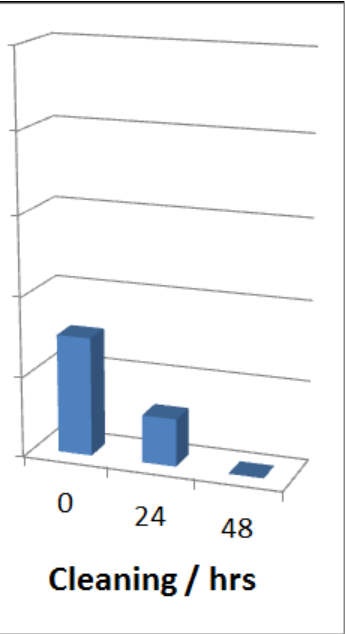

C

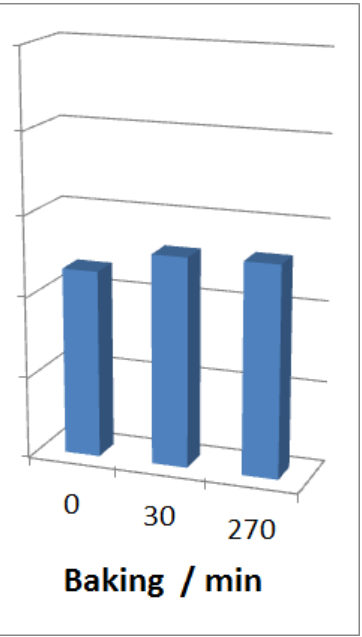

$\mathrm{D}$

Fig. 5. Plots of rate constants for contamination as a function of: a) As-installed pumping station - baking contaminated non-holey carbon films for various times; b) As-installed pumping station, plasma cleaned $\mathrm{Si}$ foil producing zero contamination in the microscope, but showing significant contamination after baking. The pumping station is contaminating the film; c) Effect of extended cleaning of the pumping station (by heating) on the contamination rate of plasma cleaned silicon foils after baking therein; d) Cleaned pumping station - the effect of baking time on the contamination rate on non-holey carbon films.

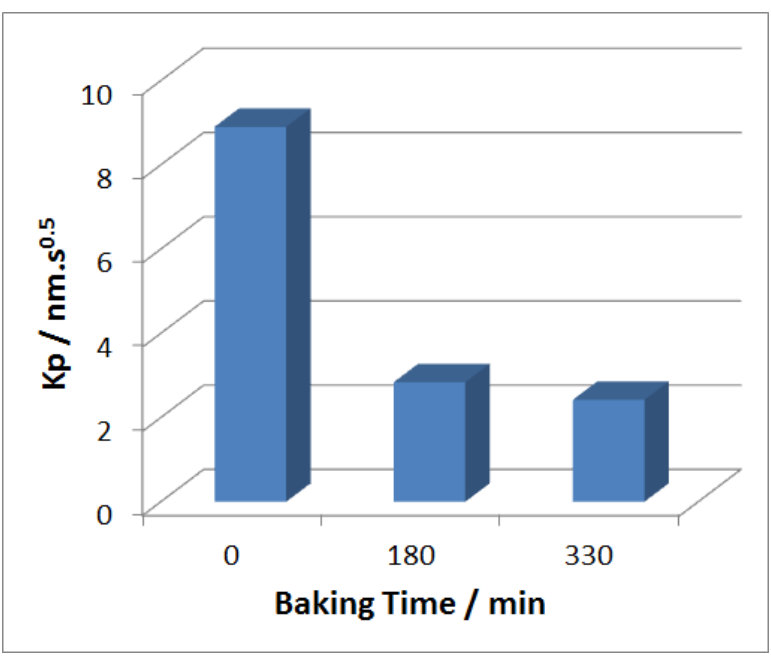

A

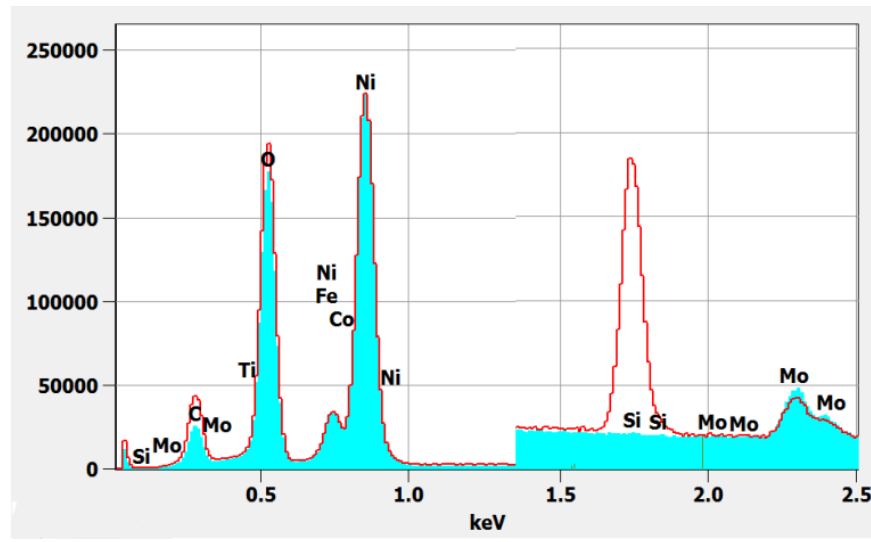

B

Fig. 6 Effect of baking time on: a) the parabolic rate constants for contamination measured on a carbon support film on which was dispered $\mathrm{PbS}$ quantum dots containing $\mathrm{MeOH}$ and TLA residues; b) EDS spectra from Nickel Oxide (on an Mo grid) thin film reference: line - as-received showing Si contamination; solid after baking for $1 \mathrm{hr}$ at $110^{\circ} \mathrm{C}$. Silcon contamination is removed completely. Note vertical scaling of right half of spectrum increased by $10 x$. 


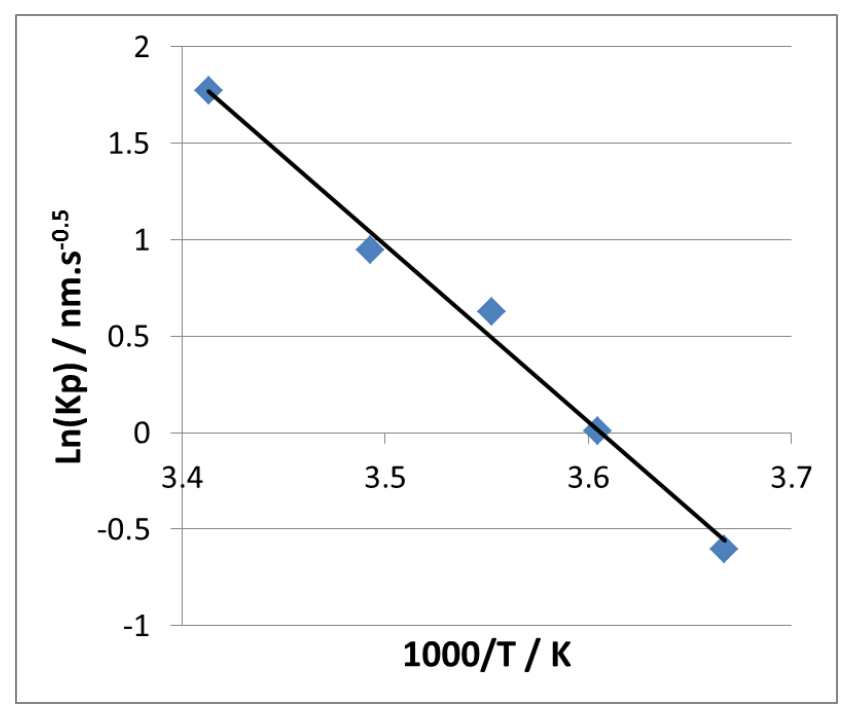

Figure 7. Arrhenius plot of the rate constant for contamination of an acetone contaminated carbon film versus reciprocal temperature. The Activation energy for diffusion is $76 \mathrm{~kJ} . \mathrm{mol}^{-1}$.

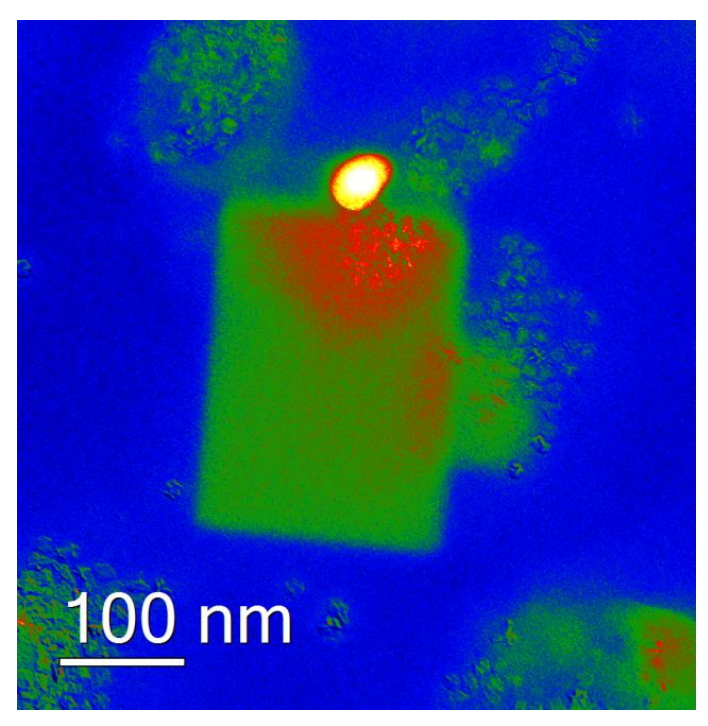

A

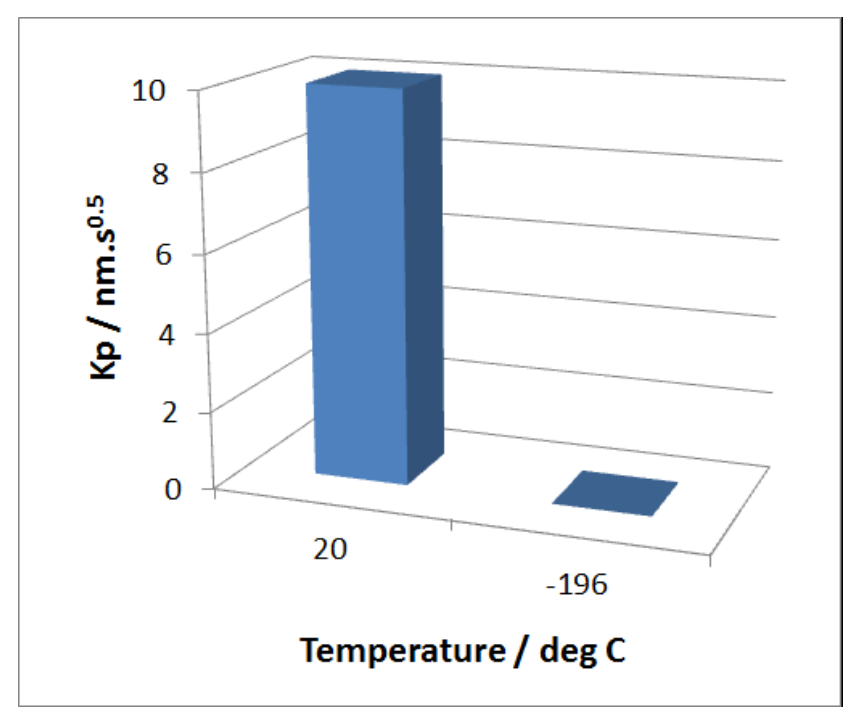

B

Fig. 8 PtNi nanoparticulates containing oleylamine on holey carbon: a) Thickness map of a region scanned for 1 minute following baking (ineffective) for 630mins. Clusters of particles act as reservoirs for hydrocarbon contamination; b) Rate constants measured for this specimen at room temperature and at liquid nitrogen temperature. Contamination stops completely at $-196^{\circ} \mathrm{C}$. 


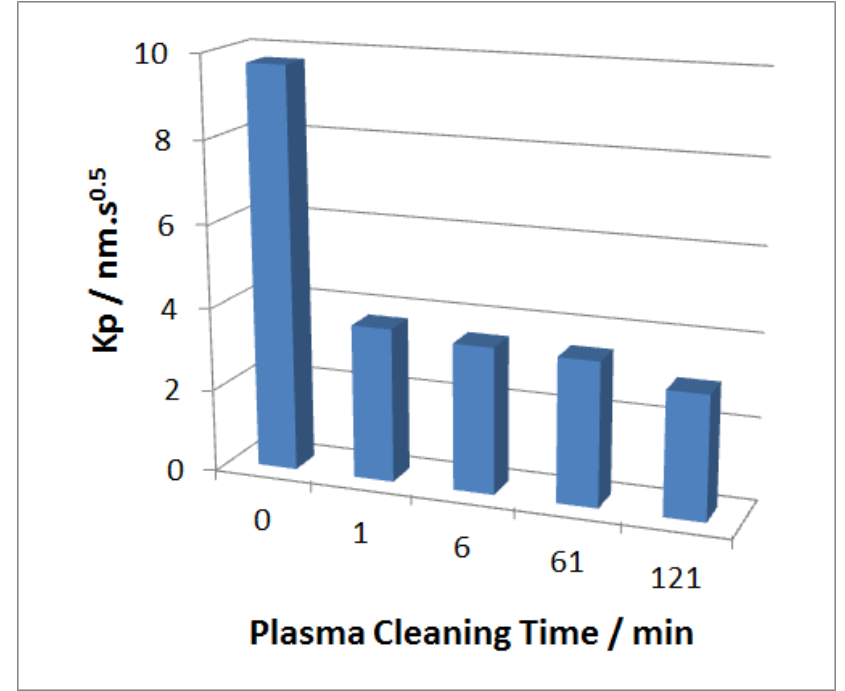

A

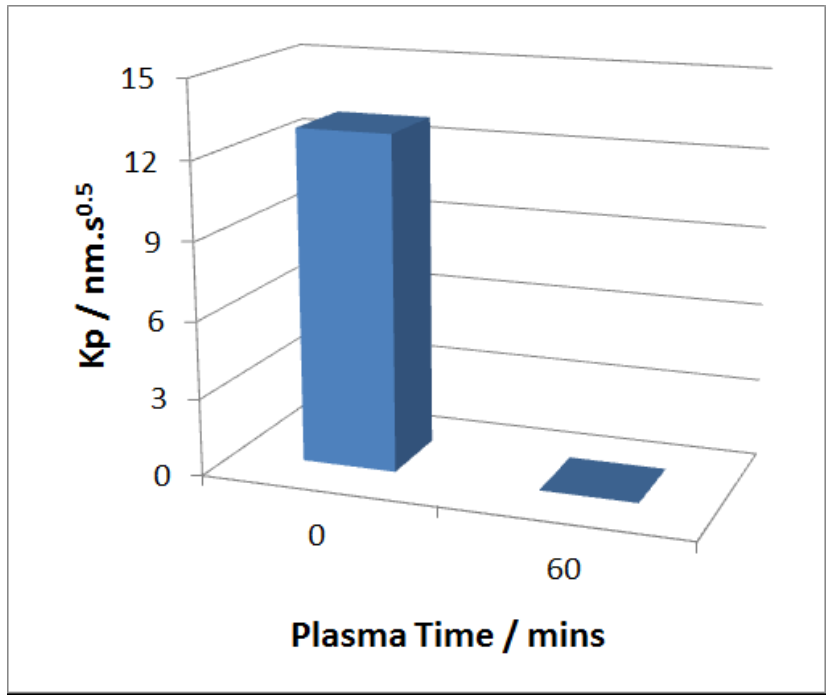

B

Fig. 9 The effect of plasma cleaning time on contamination for: a) commercial carbon support film; b) commercial gold on carbon STEM alignment reference specimen. 


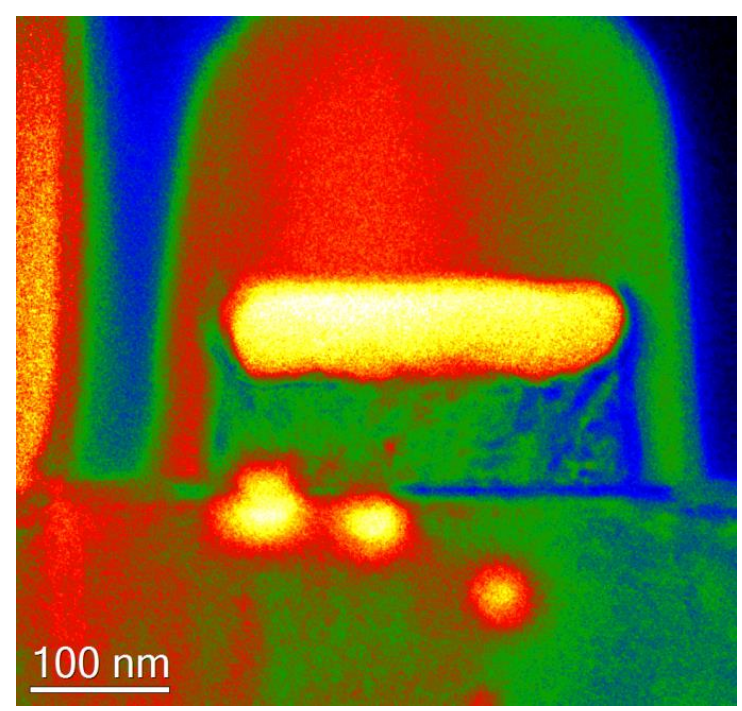

A

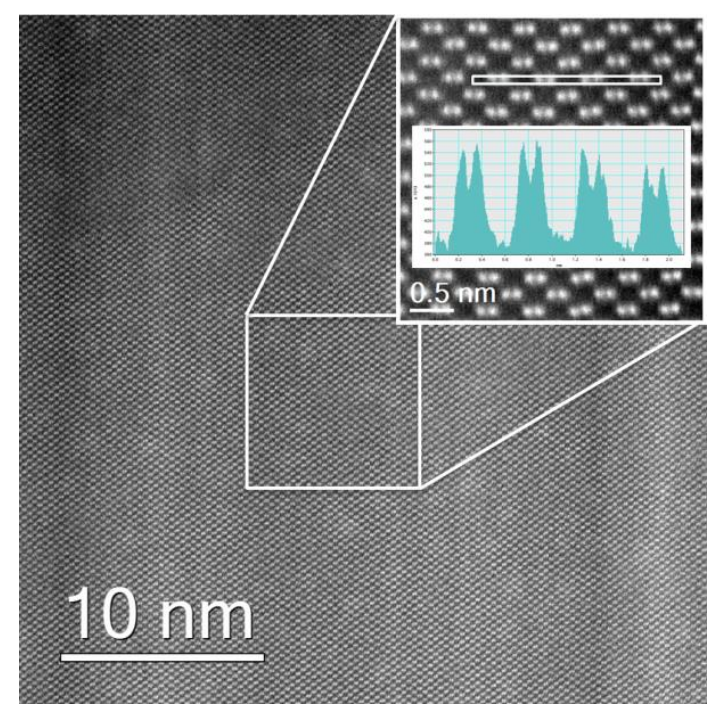

C

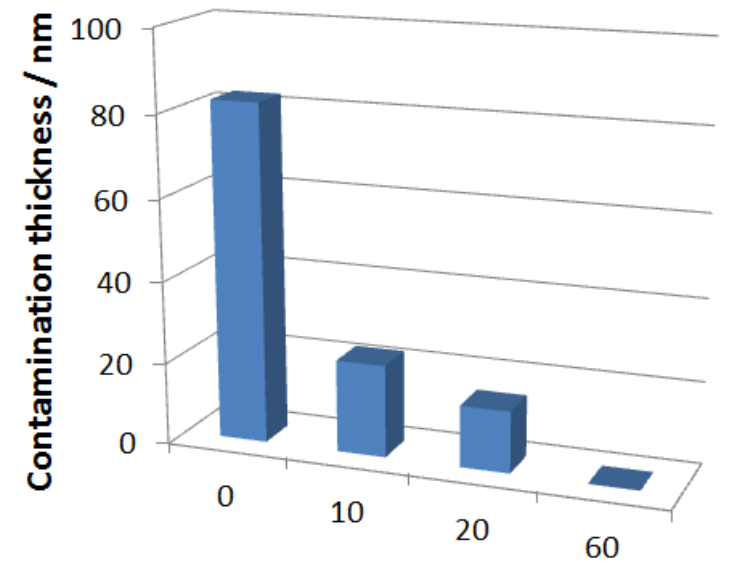

Plasma Cleaning Time / min
B

Fig. 10 Silicon Memory DRAM cross-sectional foil ( $\mathrm{Si}<110>$ ): a) Thickness map showing the as-prepared foil. The bright horizontal feature is a tungsten-containing feature. Below it, three contamination spots resulting from 30s scanning at $20 \mathrm{mx}$ can be seen. The spot intensity decreases with increasing distance from the interface with the device interface; b) Contamination thickness measured from 30 s scans at $20 \mathrm{mx}$ on a) as a function of plasma cleaning time; c) Lower magnification image $(5 \mathrm{mx})$ of a region following $1 \mathrm{hr}$ of plasma cleaning. The centre of this region was scanned at $20 \mathrm{mx}$ for $16 \mathrm{mins}$. No contamination was evident after scanning. Inset, the atomic resolution (dumbbell) contrast was preserved throughout the $16 \mathrm{~min}$ scan following plasma cleaning. 